\title{
Competitiveness of Regional Health Systems and Specific Medical Organizations in the Context of the Coronovirus Pandemic
}

\author{
Asadula Asadulaev ${ }^{1, *}$, Nadegzda Starobinskaya ${ }^{2}$, and Petr Shvetc ${ }^{1}$ \\ ${ }^{1}$ Saint Petersburg State University, Faculty of Economics, Department of Economics \& Economic \\ Policy, University embankment 7-9, 199034, St Petersburg, Russia \\ ${ }^{2}$ Herzen State Pedagogical University, Institute of Economics and Management, Department of \\ Industrial Economics and Finance, the Moika river emb., 48.St. Petersburg, Russia
}

\begin{abstract}
Research background: As the experience of a number of countries whose health systems were considered effective has shown, the pandemic has caused multiple disruptions, system overloads, and in some cases complete collapse. The negative experience made us think about what characteristics of the system and each specific medical organization are determining, and which parameters contributed to the increase of problems in the system, and which ones ensured the ability of the medical cluster or organizations to successfully function in the complex conditions of the pandemic. Consequently, mechanisms for evaluating medical institutions and clusters that would be able to monitor the health system in a normal situation and monitor its readiness for peak loads are coming to the fore.

Purpose of the article: This article is intended to identify the key factors for ensuring the competitiveness of regional medical clusters and develop a methodology for assessing the level of competitiveness of institutions in the context of a pandemic.

Methods: The methodology of evaluation is built based on modified matrices of competitiveness based on the matrix of strategic mechanisms.

Findings \& Value added: The article analyses the successful strategic practices of medical market leaders for other players and maintaining the effectiveness of the healthcare system even during global pandemics. As the scientific increment can be considered the results of analysis of mechanisms for evaluating medical institutions and clusters that could monitor the health care system in a normal situation and monitor its readiness for peak loads.
\end{abstract}

Keywords: medical organization, competitiveness of institutions, pandemic, mechanisms for evaluating medical institutions and clusters.

JEL Classification: $I 11, H 51$

*Corresponding author: asad2009@yandex.ru 


\section{Introduction}

The coronavirus pandemic has put a lot of pressure on the health systems of different countries, as a result of which many of them have shown their complete inability to withstand this blow. At the same time, by all indicators (including the competitiveness and quality of medical services) in the periods before the coronavirus pandemic, these countries appeared in the first rows of almost all known ratings [1]. However, the "rules of the game" suddenly changed, which led to a crisis in the health care system, aimed at meeting formal requirements and focusing on a marketing strategy (to the detriment of the main activity). In these conditions, health care institutions had to face new challenges, work at peak loads and constantly be in a state of search for new solutions. [2, 3]. In this situation, medical organizations did not compete for budgetary or extra-budgetary financial resources, and not for the attention of consumers, but for achieving promising results in saving their patients, and for developing new practices for the treatment and prevention of this serious disease. In the current conditions, innovative medical centers, which were previously used to the constant search and implementation of new products, were able to provide leadership.

The current situation of the pandemic has led to an impulse to cooperate with medical organizations. Previously acting more as competitors, in the current situation, organizations are forced to combine their efforts and cooperate in both medical and research processes.

Consequently, in the context of a pandemic, the competitive requirements for medical institutions are also changing. Moreover, many of the requirements that emerged during the pandemic are likely to continue and extend into the future.

As soon as the peak of the pandemic is over, people begin to go to medical institutions with previously postponed health problems. At the same time, the pandemic period has created a dual attitude towards medical organizations and their employees among the population of countries that have been subjected to a complex epidemiological situation. First, the social significance of doctors and medical organizations is increasing, which is highest in those regions where the situation was most difficult, and where the efforts of doctors saved the greatest number of patients lives. People are grateful to doctors and the health care system for saving their lives and the lives of their relatives and friends. Secondly, dissatisfaction with active interference in everyday life, the effect of prohibitions and restrictive measures is also growing. And, despite the fact that discontent is primarily caused by the government, medical institutions are also associated in the minds of the population with these unpleasant measures. In addition, some medical institutions have demonstrated a clear lack of readiness to work in critical conditions. There were many problems with the operation of permanent and temporary hospitals that were spontaneously created at the peak of the pandemic. And the fact that the population was ready to forgive during the peak of the epidemic situation is no longer a mitigating circumstance after it ends. In addition, people who are exhausted by strict restrictive measures, torn from their usual way of life, and often have serious financial problems, are becoming more critical of the gaps in the work of medical organizations. And finally, after the removal of a number of restrictive measures, there is an illusion that everything is already over. Patients do not want to comply with the requirements, explaining that neither they nor their friends and relatives were ill, so they will not get sick. And the doctors themselves, tired of exhausting, exceeding all permissible limits of work, constantly in contact with patients, often tend to lose vigilance, and sometimes they themselves violate the established requirements. This again negatively affects the competitive characteristics of the organization, which have the property of prolonged influence: the pandemic will end, and the negative mood may continue in the future.

As a result of the pandemic and quarantine measures, medical institutions may need to reassert their competitive status. Institutions will have to work carefully with both patients 
and staff to ensure that all necessary safety requirements are met, as well as provide psychological support and apply measures to reduce the level of conflicts in the health system. The problems of ensuring the competitiveness and justification of the status of medical institutions in the market of medical services may also be related to how they behaved during the peak of the pandemic. The test that the pandemic has created for medical institutions, not all passed with honor. People observed multiple instances of inappropriate behavior of medical organizations and their individual employees, which led to serious problems, untimely or poor quality of medical services, and sometimes the death of patients. All this also negatively affects the competitive status of medical organizations, which later will have to justify their mistakes or actions that are perceived by patients as such. All this forces us to develop new requirements for the competitiveness and competitive status of healthcare institutions.

\section{Methodology}

After the pandemic, it will be necessary to make adjustments to the methods for assessing the competitive status of medical institutions, as there will be a need to supplement them with new parameters that were not previously considered. One of the key factors among them is the ability to maintain a working regime in the conditions of quarantine and emergency loads that fall on the health system during a pandemic. And in these conditions, the role of the innovation factor and the ability of medical institutions to develop and implement innovative developments, develop and apply new medical technologies, and improve the effectiveness of medical actions through an innovative approach increases many times. It should be noted that in the information economy, innovations become an integral part of professional activity. [4, 5] Of course, to a large extent, this applies primarily to research in the field of Virology, toxicology, genetic engineering and improvement of medical equipment. At the same time, the ability to innovate in the field of medical developments, and in improving technologies for the treatment of all other medical areas also in high demand, increases competition status of medical institutions and, ideally, makes the institution a driver of regional economic growth and the basis for the formation of the corresponding cluster. [6 - 8] Therefore, those medical organizations that can activate their innovative potential during the crisis period will be able to cope with possible problems in the future more easily. Well, the last factor that manifests itself during a pandemic and requires inclusion in the system of assessing the competitiveness of a medical organization is the factor of stress tolerance. Not all medical organizations were able to demonstrate self-control, calmness, low level of conflicts and clear coordinated work in crisis conditions. Therefore, this indicator should be included in the system for assessing the competitive status of a medical institution, since its low indicators lead to the inability of the organization to cope with the growing workload and tougher working conditions.

To justify the choice of a promising competitive medical institution, we will develop a model based on an adjusted system of evaluation indicators and using matrix analysis tools that are well-proven for building quality assessments. In this case, the basis should be a modified methodology for assessing the competitiveness of the organization of the public sector of the economy, introduced into scientific circulation by professors N. A. Pashkus and V. Y. Pashkus. $[9,10]$ These authors developed and tested the competitiveness model for educational and cultural organizations. [11] This methodology can be supplemented with new criteria, the importance of which has become obvious in the context of the pandemic. Using the model of competitiveness of N. A. Pashkus and V. Y. Pashkus, a comparative analysis of medical organizations that claim a high status of competitiveness and are considered wealthy can be made. As a result of analytical procedures, 
recommendations can be given on effective behavior during a pandemic and the choice of a competitive strategy for medical organizations for the period of further development.

The model assumes an assessment of multi-criteria characteristics that determine the contribution of a medical institution to its competitive status, which should be used to construct marginal replacement coefficients for each qualitative criterion for evaluating a medical organization. The second system of criteria is used to assess the specifics of the medical services market in the study region, where the model is being tested. According to this system of indicators, marginal replacement coefficients should also be estimated, which will allow us to weigh the vectors that characterize the attractiveness of the selected type of medical services market in the analysed region. Integration of assessments is based on the competitiveness matrix formed by N. A. Pashkus and V. Y. Pashkus using conceptual approaches for positioning business processes based on the GE/McKinsey matrix. The position of the parameters of a medical organization on the competitiveness matrix will show the area to which the organization can be assigned and the strategic guidelines that it assumes. Therefore, it will be possible to carry out a comparative analysis of the competitive positions of healthcare organizations in the selected region. Further, it is possible to determine the directions of their further functioning after the pandemic in the medical services market.

The main parameters of the model will be evaluated using matrix algorithms. Let each group of indicators, namely the assessment of competitive status and the assessment of market attractiveness, be defined by a system of vectors, each of which is a qualitative assessment of the organization according to a selected system of criteria. Then, for matrix (1), the marginal replacement coefficients of each criterion can be calculated by entering eigenvalues and vectors of the matrix (see formula 2).

The competitiveness matrix is generally defined as follows: $\left(\begin{array}{ccc}a_{11} & \ldots & a_{1 n} \\ \ldots & \ldots & \ldots \\ a_{n 1} & \ldots & a_{n n}\end{array}\right)$,

here $\mathrm{a}_{i j}$ is the coefficient of influence of $i$ criterion competitive status or attractiveness of the market of medical services on his $j$ criterion, likewise, it is the assessment of the impact of the selected criteria to analyze medical facility.

Estimates of the eigenvector values are made as roots of a degree equal to the dimension

$$
\begin{aligned}
& A_{1}=\sqrt[n]{a_{11} \cdot a_{12} \cdot \ldots \cdot a_{1 n}} \\
& \text { of the competitiveness matrix: } A_{2}=\sqrt[n]{a_{21} \cdot a_{22} \cdot \ldots \cdot a_{2 n}} \\
& A_{n}=\sqrt[n]{a_{n 1} \cdot a_{n 2} \cdot \ldots \cdot a_{n n}}
\end{aligned}
$$


Then the eigenvector indicating the priority of each criterion or each medical institution

for the selected criterion will be evaluated as a vector:



The estimates obtained using formula (3) can be included in the integrated assessment of the competitive status or attractiveness of the market for each medical organization included in the assessment. Further, the obtained integral characteristics can be plotted on the competitiveness matrix (see Fig. 1).



Fig. 1. The matrix of competitiveness of universities

Shown in Fig. 1 the areas of competitiveness of medical institutions are divided into three main groups. The first group: this is the area of winners, among which the winner \#1 is the leading position, the winner \#2 has a lower market potential, the winner \#3 is not fully held in its competitive status. The second group is intermediate, where organizations that are at the stage of self-determination of strategic development are concentrated. All organizations that occupy intermediate positions are in an unstable situation, which makes them highly vulnerable at the moment. Given the fact that the pandemic and its consequences make significant adjustments to the life of all organizations, and the market environment in the context of a pandemic is characterized by a high level of instability and risks, organizations that have received the status of intermediate ones are in a very unprofitable competitive role. Intermediate \# 1 has the highest growth potential among intermediate organizations, but this organization has not yet taken place in a competitive plan, which requires it to make significant efforts to form a competitive status, and the position of intermediate \# 3 is extremely unstable, leading to the possibility of a sharp closure of the market in which it specializes. Despite the rapid growth of those who want to get a profession in the field of medicine and the interest of the whole world in the field of medicine, not all areas of medical services are now equally in demand. For example, plastic surgery and other expensive hardware methods of cosmetology, which were previously highly competitive and provide high revenues from commercial activities, are currently experiencing a bad time. This is due to a drop in the income level of the typical target audience of this type of medical services, and the fact that there is a real threat to life and health, and restrictive measures, first of all, affected this sphere of medical services, which 
is not critical for the life support of citizens. The third group of organizations, whose indicators fell into the field of losers, demonstrates a low competitive level and is inferior in competition. Positions differ only in the degree of proximity to the critical state of existence. For all of them, it is necessary to take some reasonable measures to overcome the crisis and identify a strategic direction in which they can succeed in the long term.

We will formulate a system of criteria that will be used in the future to evaluate the competitive properties of several medical institutions in St. Petersburg that specialize in innovation. For this purpose, we will set criteria for evaluating the competitive status of medical institutions, which should include:

1. Relative market share of a medical institution for the selected main business profile;

2. Ability to ensure high real and perceived quality of medical services;

3. The Ability to attract and maximize the human potential of leading medical personnel in medical and research fields;

4. The uniqueness of the resource potential of medical institutions and implemented by them in their profile, the level of innovative capacity and ability to innovate;

5. The level of technological and material equipment of processes in a healthcare organization;

6. Share of budget and preferential medical programs to serve the population and increase the level of access to medical services;

7. The territorial accessibility of medical institutions;

8. the volume and amount of subsidies, grants and other additional financial resources attracted to the medical institution;

9. Stress tolerance and the ability to control the efficiency of work in conditions of increased loads and additional requirements for the system.

The developed system of indicators will allow evaluating the characteristics of a medical institution along the horizontal axis of the competitiveness matrix. The system of indicators for evaluating the value along the vertical axis of the matrix determines the potential and attractiveness of the selected market for medical services in a particular region. The following market characteristics should be included in this system:

1. Potential capacity of the market of medical services of this profile in the region;

2. Features of competition in the selected segment of medical services;

3. Potential dynamics of the volume of medical services provided on a reimbursable basis and the volume of the insurance Fund for mandatory and voluntary medical insurance programs;

4. Restrictions and requirements for implemented medical technologies and public and private investments in their development;

5. the level of risks of conducting medical activities and potential threats to the stability of the existence of medical institutions;

6. The level of uncertainty and variability in the external environment in which it is necessary to work in medical institutions.

Indicator systems for different axes of measuring competitiveness may have a different number of initial vector characteristics, since as a result of applying the procedure described above, the vectors are collapsed to an integral characteristic of the competitive status and market attractiveness of each medical institution. Therefore, these characteristics determine the coordinates of the matrix for the selected medical organization and allow us to judge its position on the matrix.

\section{Results}

Consider several medical organizations in St. Petersburg that implement innovative activities and offer consumers a range of unique services. We study the strategies of these 
organizations and make a comparative assessment of their competitive position based on the model introduced in this paper. Analysis of the St. Petersburg medical market reveals several organizations that demonstrate high efficiency potential, both in terms of patient recovery, and in terms of their ability to attract and efficiently use additional resources to the organization's budget. Among these organizations are the following institutions:

1. FSBMEE Military medical Academy. S. M. Kirov MO of Russia (1)

2. The Federal Children's scientific-clinical center of infectious diseases of the Federal medical-biological Agency of Russia (MD, PhD GNCCI FMBA Rossii) (2)

3. FGBU the Institute of experimental medicine Russian Academy of Sciences (IEM RAS) (3)

4. FSBI "SMRC them. V. A. Almazov" Of Ministry Of Healthcare (4)

These organizations implement many of their own innovative approaches and apply their own highly effective technologies for treating and diagnosing patients. During the pandemic, all of them demonstrated high stress tolerance and retained the ability to carry out large-scale research, including in the field of treatment and prevention of coronavirus infection, in particular, in people with a number of severe diseases that complicate the course of the disease. All these institutions have demonstrated a high level of coherence and the ability to monitor compliance with all necessary regulations and restrictive measures in place during the peak of the pandemic.

At the same time, there are two other medical institutions in the city that claim to be organizations specializing in innovation. At the same time, these health organizations demonstrated a high enough resistance to stress and ability to control that in the period of the pandemic has led to the emergence of dangerous situations. Moreover, with the perceived high quality of services, their real innovative characteristics do not always fully correspond to the stated ones. Among these medical institutions, you can specify:

1. Nikiforov all-Russian center for emergency and radiation medicine of the Ministry of emergency situations of Russia (5)

2. A.A.Smorodintsev Federal state budgetary research Institute of Influenza of the Ministry of health of the Russian Federation (6)

We will conduct a comparative analysis of these medical institutions in the city and identify promising areas for their strategic development in the context of the pandemic. Using the system of criteria introduced above, we will evaluate marginal replacement coefficients for the competitive status and attractiveness of the market for all six medical institutions. The obtained characteristics for all organizations are plotted on the area of the competitiveness matrix (see Fig. 2). 


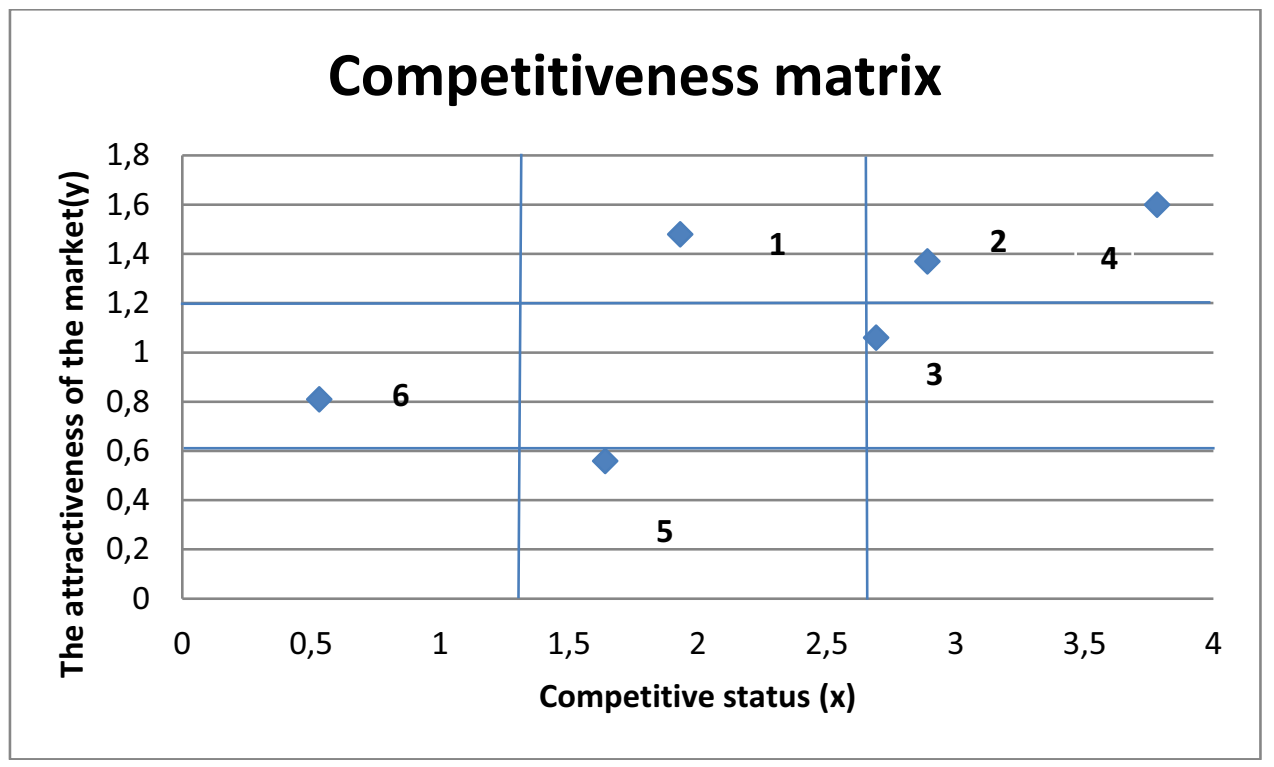

Fig. 2. The matrix of competitiveness in six of the studied medical institutions of Saint-Petersburg

The analysis showed that four organizations that demonstrate high values of innovative abilities, stress tolerance and control were in the winner zones. Among them, the best position is FGBU "SMRC them. V. A. Almazov" Ministry of health of Russia (4), which in the last few years has made a huge leap forward, and provides an undeniable uniqueness of implemented developments and medical technology. In the second position in the same field, the winners are \# 1, i.e. Among the market leaders, there is the children's research and clinical center for infectious diseases of the Federal medical and biological Agency of Russia (FGBU DNKCIB FMBA of Russia) (2), only slightly inferior to the first organization. The winner area \# 2 includes THE Kirov military medical Academy of the Ministry of defense of Russia (1), which is not currently a leading organization due to its insufficiently strong competitive status, therefore, this organization should make efforts in the future to develop its competitive status and form the perceived qualities of its medical services. At the same time, measures should be taken to strengthen the strengths of the organization's key innovations. Finally, the fourth place was taken by the Institute of experimental medicine of the Russian Academy of Sciences (IEM RAS) (3), which was in the field of winners \# 3. This institution should pay attention to the selection of its most attractive market segment and focus on strengthening the status of an innovative competitor in this particular segment.

Two organizations that were unable to meet all the requirements of the crisis period, and showed insufficiently high indicators of stress resistance, were in the field of losers. Thus, the Smorodintsev research Institute of Influenza of the Ministry of health of the Russian Federation (6) was in the best of the worst areas - the loser \# 1, which requires the organization to identify a clear strategy for market behavior, protect its competitive status and develop resource potential in the selected promising segment of the medical services market. The last place was taken by the all-Russian center for emergency and radiation medicine. A. M. Nikiforova EMERCOM of Russia (5), which is in the losers ' area \# 2, where the attractiveness of the market is not very high, which is caused by the blurred positioning of the center and an insufficiently thought-out policy of promotion in the market. 


\section{Discussion}

The refined model proposed in the article allows us to assess the competitiveness of medical organizations. However, its effective use is associated with a number of problems:

First, the focus of perception of competitiveness has shifted to the active use of innovations. This is due to the fact that during the pandemic, people clearly observed the success of those medical organizations that actively conducted innovative activities. In addition, this period has shown that various unpredictable phenomena can occur that have an extremely negative impact on a person, and no one guarantees that the coronovirus will loosen its grip, but some other, perhaps even more severe virus will appear, or another problem may appear that forms a serious challenge to the medical system and specific medical organizations. All this is compounded by a large amount of fake news [12]. All this has led to a shift in focus from providing quality medical care to applying innovations in treatment.

Secondly, the pandemic has clearly shown that one of the main factors of a competitive health system is its availability. Focusing on expensive medicine, expensive medical services, and expensive insurance allows you to build an excellent health care system by all indicators [13 - 15]. Research shows that such health systems have low competition in the market for people whose health differs from the ideal [16]. However, excessively high prices create a high entry barrier and low availability, which leads to the rapid spread of the epidemic.

Third, the politicization of the introduction of quarantine measures. A person is annoyed by the excessive measures taken by medical organizations after overcoming the peak of the pandemic, it seems to him that his problems have been left aside, and he is, again, dissatisfied with the government and medical institutions. The deputies, in turn, support this activity for populist reasons [17 - 19], this leads to changes in competitive factors.

Fourth, this model does not reflect one of the focuses of Russia's economic policyimport substitution [20]. Import substitution (especially export - oriented) changes the performance criteria and strengthens some of them.

Thus, taking into account these factors and the need for further research that can solve the above problems, the system is quite ready to determine the competitiveness of health care institutions.

\section{Conclusion}

The simulation results confirm the fact that in the context of a pandemic and increasing demands on health care institutions, factors of innovation, stress tolerance and control over all processes are becoming critical. Those medical institutions in St. Petersburg that failed to demonstrate high efficiency in these indicators fell to unattractive competitive positions. At the same time, institutions that are able to ensure the uniqueness of their developments, teamwork, and compliance with all requirements and restrictions have reached a leading competitive position.

\section{Reference}

1. Kislitsyna, O. A., Chubarova, T. V. (2020) The Use of Composite Indices to Measure the Activities of the Health Care System: The International Experience. Problems of modern economy, 2, 100-104

2. Maani, N., Galea., S. (2020). COVID-19 and Underinvestment in the Health of the US Population. The Milbank Quarterly, 98(2), 239-249. 
3. Diez Roux, A. V. (2020). Population Health in the Time of COVID-19: Confirmations and Revelations. The Milbank Quarterly, 98(3), 629-640.

4. Porter, M. E. (1998). Clusters and the New Economics of Competition. Harvard Business Review, 76(6), 77-90.

5. Kamenica, E. (2017). Information Economics. Journal of Political Economy, 125(6), 1885-1890.

6. Segerstrom, P. (1991). Innovation, Imitation, and Economic Growth. Journal of Political Economy, 99(4), 807-827.

7. Herzik, Yu. G. (2017). Formation of cluster systems in the field of healthcare and the medical industry. Economics and Management: Problems, Solutions, 4(5-2), 23-27.

8. Pashkus, V., Pashkus, N., Chemlyakova, A. (2017). Model for Assessment of Healthcare Institutions'Competitiveness. In P. Hajek et al. (Eds.), CBU International Conference Proceedings 2017 (pp. 361-365). Prague, Czech Republic.

9. Pashkus, N. A. et al. (2019). Cultural City Brands and Global Competitiveness. Revista San Gregorio, 36, 197-209.

10. Pashkus, V., Pashkus, N., Chemlyakova, A. (2017). The Problem of Quality Correlation and Efficiency of Medical Services as a Factor of Health Organizations Competitiveness. In P. Hajek et al. (Eds.), CBU International Conference Proceedings 2017 (pp. 366-370). Prague, Czech Republic.

11. Starobinskaya, N. M. (Ed.) (2019). Socio-cultural sphere in the new economy: from the development of education to the art market. St.Petersburg: KultInformPress.

12. Massey, G., Kliestikova, J., Kovacova M., and Dengov, V. V. (2018). The Perceived Accuracy of Fake News: Mechanisms Facilitating the Spread of Alternative Truths, the Crisis of Informational Objectivity, and the Decline of Trust in Journalistic Narratives. Geopolitics, History and International Relations, 10(2), 37-43.

13. Cooper, Z., Craig, S. V., Gaynor, M., Van Reenen, J. (2019). The Price Ain't Right? Hospital Prices and Health Spending on the Privately Insured. The Quarterly Journal of Economics, 134(1), 51-107.

14. Einav, L., Finkelstein, A., Mahoney, N. (2018). Provider Incentives and Healthcare Costs: Evidence From Long-Term Care Hospitals. Econometrica, 86(6), 2161-2219.

15. Kitagawa, T., Tetenov, A. (2018). Who Should Be Treated? Empirical Welfare Maximization Methods for Treatment Choice. Econometrica, 86(2), 591-616.

16. Harris, M. C., Kohn, J. L. (2018). Reference Health and the Demand for Medical Care. The Economic Journal, 128(615), 2812-2842.

17. Rodrik, D. (2018). Populism and the economics of globalization. Journal of International Business Policy, 1, 12-33.

18. Harstad, B. (2020). Technology and Time Inconsistency. Journal of Political Economy, 128(7), 2653-2689.

19. Elliott, M., Golub, B. (2019). A Network Approach to Public Goods. Journal of Political Economy, 127(2), 730-776.

20. Aliaskarova, Zh., Pashkus, V., Blagikh, I. A. (2020). Proactive Industrial Policy as the Main Strategy for Improving Russia's Competitiveness in the Context of Global Economic Processes. In T. Kliestik (Ed.), Proceedings of 19th International Scientific Conference Globalization and Its Socio-Economic Consequences - Sustainability in the Global-Knowledge. Rajecke Teplice, Slovakia. 